\title{
Attitudes and Preferences for Sex-Appealing Products by Vietnamese Women in Their Ovulation Cycle
}

\author{
Ngoc Pham, Arturo Vasquez, Reto Felix \\ The University of Texas Rio Grande Valley, Rio Grande Valley, TX, USA \\ Email: ngoc.pham01@utrgv.edu, arturo.vasquez@utrgv.edu, reto.felix@utrgv.edu
}

How to cite this paper: Pham, N., Vasquez, A. and Felix, R. (2017) Attitudes and Preferences for Sex-Appealing Products by Vietnamese Women in Their Ovulation Cycle. Theoretical Economics Letters, 7, 1986-2007. https://doi.org/10.4236/tel.2017.77135

Received: October 23, 2017

Accepted: November 25, 2017

Published: November 28, 2017

Copyright $\odot 2017$ by authors and Scientific Research Publishing Inc. This work is licensed under the Creative Commons Attribution International License (CC BY 4.0).

http://creativecommons.org/licenses/by/4.0/

\begin{abstract}
This study investigates the impact of female sex hormones on women's consumption of fashion products. These hormones reach peak level when women are near ovulation, and this research examines how these hormones, when at peak level, influence women's attitudes and purchase intention towards sexy and revealing fashion products. The research is based on two theoretical frameworks: Ovulatory Shift Hypothesis (OSH) and Theory of Reasoned Action (TRA). Specifically, the OSH, based on the female ovulatory cycle, postulates that women change their sexual preferences for men with perceived good biological indicators of genetic fitness on the high-to-low fertility days of the cycle. Thus, these women may also exhibit increased mating interest and higher motivation to act in ways that would help secure a desirable partner. The theory of reasoned action sheds light on the indirect relationship between women's ovulatory period and their choice of apparel, with attitude as a mediator. A within-subject survey design was used to examine the proposed phenomenon. Vietnamese women were recruited for this specific study. In line with OSH, these study findings suggest that when near ovulation, women show more favorable attitudes and stronger purchase intention towards sexy and revealing fashion products. Further, as predicted by TRA, attitudes towards sexy and revealing fashion products mediate the relationship between ovulation and purchase intentions. The results of this study add to related streams of research which suggests that hormonal fluctuations influence consumers' attitudes and purchase intention. For managers, the results provide suggestions on how to target female consumers for sexy fashion products more effectively.
\end{abstract}

\section{Keywords}

Revealing Fashion Products, Peak Fertility, Purchase Intention 


\section{Introduction}

The marketing literature contains a significant number of studies that apply theories from sociology, psychology, anthropology, and economics to discuss marketing phenomena. However, only a handful of empirical studies exist that help us understand how biological processes influence business decisions in marketing. Moreover, it is impossible to make a direct link between the human biological traits and their consumptions. Therefore, evolutionary psychology plays the role of a causal link between these natural and social sciences in the sense of explaining the phenomena of culture by its biological underpinnings, with psychology as the intermediate link [1]. In other words, evolutionary psychology relies on the basic tenet that the human mind is a result of an evolutionary process that operates on the principle of natural selection. It helps explain marketing phenomena, especially consumer behavior [1]. Given the increasing acceptance of evolutionary psychology in the scientific community, Bagozzi and Nataraajan [2] espouse a need for creative research applying this framework to marketing.

Thus, there is a call for further investigation concerns questions relating to how women's ovulation influences their preferences and purchase intentions. Indeed, one critical marketing problem the fashion industry faces is how to market fashion products to women [3]. Considering women's ovulatory cycles is a promising strategy to understand this issue. Previous research [4] [5] [6] suggests that women's preference for and selection of sexy and revealing outfits shifts when they are near ovulation (i.e., at peak fertility). However, previous research on the influence of women's ovulatory cycles on product preferences and purchase intentions suffers from three important limitations. First, these studies have been conducted typically in a lab setting, which affects their realism and external validity. Second, previous research has relied predominantly on consumers from the US or other Westernized countries, and it remains unclear if the results are valid in different cultural contexts. Third, important mediating effects have been neglected so far, mainly because efficient statistical tools to test for mediation in repeated measurement designs (i.e., within-subject designs) have only recently developed [7]. Forth, there is a need to consider the moderating effects of important psychological and demographic traits on the relationship between women's ovulation and their preference towards revealing and sexy fashion products.

The current research addresses these issues and proposes the following research questions. First, how do women's ovulatory cycles influence attitudes and purchases intentions towards sexy and revealing fashion products? Second, do Asian women, particularly Vietnamese women, as compared to American encounters show different attitudes and/or purchase intention towards these products? Third, do women's attitudes towards sexy and revealing fashion products have a mediating effect between women's ovulatory cycles and their purchase intentions for sexy and revealing fashion products? And forth, are there personality-related 
moderating variables that may influence the direct and/or indirect effect of ovulation on purchase behaviors?

Moreover, following Burgess and Steenkamp's [8] call for more research in emerging markets to take into account the typically "significant socioeconomic, cultural, and regulative departures from the institutional assumptions of Western countries" (p. 1), this research relates to a collectivist Asian economy, Vietnam.

In order to answer the proposed research questions, three areas in the literature are reviewed: 1) Ovulatory Shift Hypothesis (OSH), which helps explain the changes in women's attitudes and purchase intention toward sexy and revealing fashion products; 2) Theory of Reasoned Action (TRA), which helps provide the theoretical framework for the mediating role of attitudes; and 3) the influence of sexy fashion-consciousness and self-control on appearance-related fashion consumption.

The following sections revise relevant literature, present the methods used in the research and the results obtained, discuss the theoretical and managerial implications, and propose some limitations and future research.

\section{Literature Review}

\subsection{Ovulatory Shift Hypothesis}

The Ovulatory Shift Hypothesis (OSH) [9] is based on the ovulatory cycle, a monthly occurrence for most women from the first menstrual period to approximately 50 years of age [10]. The cycle is characterized by specific hormonal changes during several days around the ovulation of women who are fertile.

This hypothesis, based on women's reproductive biological nature, underscores the heavy costs of parental investment placed on women [11]. Women bear heavier obligations of parental duty than men, thus they unconsciously tend to be more selective in critical sexual decisions such as the choice of partners, the timing of sexual intercourse, and reproduction [9]. Moreover, OSH postulates that women change their sexual preferences for men with perceived good biological indicators of genetic fitness on the high-to-low fertility days of the cycle. For reproductive purposes, women near ovulation become choosier regarding mates and unconsciously favor males they perceive to carry good genes. Furthermore, these women may also exhibit increased mating interest and higher motivation to act in ways that would help secure a desirable partner.

The literature provides evidence that women in general tend to use fashions to increase their competitiveness when there are threats from direct rivals, the presence of desirable partners, or both (see, e.g., [4] [5] [11]). Women purchase conspicuous fashions primarily to deter rivals to their own current or potential romantic relationships (see, e.g., [12] [13]). For example, a recent study suggests that women may use luxury products to signal to other women that her romantic partner is especially committed to her [12].

In addition, women tend to make an effort to appear more youthful and at- 
tractive to impress their romantic partners (see, e.g., [14] [15]). Literature indicates that physical attractiveness has been found to be a dimension of utmost concern among women [1], for example, women consistently scored higher than men on clothing concern and public body consciousness. As a result, under the influence of hormone-mediated changes in sexual interest and sociability, shifts in clothing preference toward revealing and sexy products may be enhanced (see, e.g., [16] [17]). More specifically, women generally feel greater sexual desire around the time of ovulation, and thus they may be motivated to dress more attractively and appealingly.

Similarly, Saad and Stenstrom [18] conducted a similar study on women's appearance-related consumption across their ovulatory cycle. Relying on a survey panel, women's food and appearance-related consumption was tracked for 35 consecutive days. The results indicate that appearance-related desires, dollars spent, and beautification behaviors increased during the fertile phase, whereas food-related desires, dollars spent, and eating behaviors were greater during the non-fertile phase.

In short, to compete for desirable mates, women, when near ovulation (i.e., the time they are most likely get pregnant), try to stand out from the crowd of female competitors. That is, for mating purposes these women use fashion to create appearances that highlight their youth and physical attractiveness (see, e.g., [19] [20]), and they also use fashion to deter direct rivals from pursuing the romantic partners that have attracted their interest [12].

In a recent study, researchers asked women to sketch outfits that they would want to wear to social gatherings when young, attractive women and single men would be present. When near ovulation, the outfits some women drew were more revealing and sexy than those drawn by them when were not near ovulation (see, e.g., [4] [21]). Another study by [5] showed that highly fertile women were more likely to pick revealing and sexy garments during a shopping task on a simulated retail website than were women who were not ovulating. Thus, ovulation apparently prompts highly fertile women to dress in a provocative manner. Therefore, we hypothesize the following:

H1a: Women's ovulation has a significant and positive effect on their attitudes toward sexy and revealing fashion products.

H1b: Women's ovulation has a significant, positive, and indirect effect on their purchase intention toward sexy and revealing fashion products.

\subsection{Theory of Reasoned Action}

The Theory of Reasoned Action (TRA) includes the four variables: subjective norms, attitude, purchase intention, and actual purchases (see, e.g., [22] [23] [24]). According to this theory, individuals' attitudes and subjective norms influence their purchase intention, which in turn affects behavior. Attitudes may involve the perception of whether an action is right or wrong. The subjective norm for an act may lead to an assessment of how others will judge the act. In the light of this theory, women's attitudes toward sexy and revealing fashions have a mediating 
effect on the relationship between women's ovulation and their purchase intention for revealing and sexy fashion products.

Thus, based on TRA, we hypothesize the following:

H2: Attitudes towards sexy and revealing fashion products mediate the relationship between women's ovulation and their purchase intentions.

\subsection{Moderating Effects: Sexy Fashion Consciousness and Self-Control}

Fashion consciousness refers to the degree of interest people have in fashion in terms of the time and effort they expend in fashion-related activities [25]. Previous research suggests that an important difference exists in fashion consciousness between developed and less developed countries, as well as between the East and the West [25]. For example, within the Western individualist culture, an individual is seen as independent, autonomous, and separate from society [26], and fashion enables a person to be perceived as unique among peers. Their Asian counterparts, on the other hand, typically prefer to wear clothing that facilitates acceptance by their peers. That is, within Eastern collectivism culture, a great emphasis is placed on: 1) the views, needs, and goals of the community rather than of oneself; 2) social norms and duty defined by the in-group rather than behavior to get pleasure; and 3) beliefs shared with the community rather than beliefs that distinguish oneself from in-group [27].

Another important facet of fashion consciousness refers to a person's degree of involvement with a style of clothing (see, e.g., [28] [29]). According to [30], the more important the role fashion plays in women's lives, the greater their involvement with fashion will be. Generally speaking, individuals are interested in clothing because it gives them pleasure and helps them to express their identity (see, e.g., [31] [32]). It is not surprising, then, that fashion marketers heavily employ the basic evolutionary incentive, sex, to satisfy customers' motivations for consuming and sustain their attachment to fashion items. Thus:

H3a: Sexy fashion consciousness has a moderating effect on the relationship between women's attitudes and their purchase intention toward sexy and revealing fashion products.

A second variable that may potentially moderate the relationship between ovulation and attitudes towards sexy and revealing fashion products is self-control. Self-control is the capacity to resist temptation, especially those relevant to impulsive purchases and other expenditures that are likely to be regretted later on (see, e.g., [33] [34]). It is assumed that the more self-control individuals have, the less likely they are to purchase expensive or sexy and revealing products.

The literature shows that both internal and external forces can control, facilitate, or impede performance of a behavior [23]. Skill and willpower are the internal locus of control for the individual while task demands and others' actions are the external forces [22]. Self-control is the inner locus of control because it refers to the degree to which a person is capable of resisting an urge to perform certain acts. 
This research examined the concept of self-control to understand the moderating effect of females' self-control on their purchase intention. It is assumed that the more self-control women have, the less likely they will be to purchase expensive, sexy, and revealing fashion products. Thus, the following hypothesis is proposed:

H3b: Self-control has a moderating effect on the relationship between women's attitudes and their purchase intention towards sexy and revealing fashion products.

\section{Method}

\subsection{Selection of Sexy and Revealing Fashion Products}

To select fashion products for the main study that respondents would perceive as sufficiently sexy and revealing, we conducted a pre-test with 143 Vietnamese female consumers (mean age $=29.63$ years, range from 21 to 50 years). This group was different from the 66 respondents who participated in the main survey.

Participants saw four fashion products in each of four categories: handbags, shoes, skirts, and tops, which made a total of 16 fashion products (Figures A1-A8 and Figures B1-A8). The products for the pre-test were chosen from an array of products offered on a popular retail merchandise website and drawn from examples in Vogue and Cosmopolitan, two fashion magazines aimed at women. The sexy and revealing merchandise selected for the pre-test was sexy, but not blatantly sexual. Whether the fashion products were sexy or revealing was assessed in line with (see, e.g., [4] [5]).

For example, shoes which were not considered sexy include "brown flat shoes" (Figure A1) and "black flat shoes" (Figure A2). These rather plain-looking products were selected at a popular department store website by means of samples featured in Vogue and Cosmopolitan. Durante's [5] Figure A1 of undecorated flat-heeled shoes had been used as a guide for the choice.

Relatively sexier shoes include "red heels" (Figure B1) and "golden heels" (Figure B2). These two items look a bit sexier in terms of their vivid colors and ornamental design. More often than not, high-heeled shoes or boots are made from lace, velvet, leather or latex incorporated with strings or decorations, and they are deemed fancier or more sensual.

Out of the 16 products evaluated, the eight ones with the highest mean scores on sexiness and revealingness were used in the study (see Table 1).

\subsection{Survey on How Likely Vietnamese Women Are to Provide Information of Their Ovulation Cycle}

Since women's ovulatory cycle represents relatively intimate information, it can be argued that consumers may be more reluctant to provide such information than on demographic facts such as the age or income.

To address this concern, an additional study that aimed to understand if Vietnamese women were willing to share sensitive information regarding their ovulation 
Table 1. Revealing and sexy fashion products and less revealing and sexy fashion products.

\begin{tabular}{|c|c|c|c|c|}
\hline \multirow[b]{2}{*}{ Fashion Products } & \multicolumn{2}{|c|}{ Revealingness } & \multicolumn{2}{|c|}{ Sexiness } \\
\hline & Mean & $\begin{array}{l}\text { Standard } \\
\text { Deviation }\end{array}$ & Mean & $\begin{array}{l}\text { Standard } \\
\text { Deviation }\end{array}$ \\
\hline $\begin{array}{l}\text { Brown flat shoes } \\
\text { (Figure A1) }\end{array}$ & & & 3.066 & 1.681 \\
\hline $\begin{array}{l}\text { Black flat shoes } \\
\text { (Figure A2) }\end{array}$ & & & 3.507 & 1.689 \\
\hline $\begin{array}{l}\text { Red heels } \\
\text { (Figure B1) }\end{array}$ & & & 4.889 & 1.570 \\
\hline $\begin{array}{l}\text { Golden heels } \\
\text { (Figure B2) }\end{array}$ & & & 5.220 & 1.551 \\
\hline $\begin{array}{l}\text { White handbag } \\
\text { (Figure A3) }\end{array}$ & & & 4.492 & 1.408 \\
\hline $\begin{array}{l}\text { Brown handbag } \\
\text { (Figure A4) }\end{array}$ & & & 4.125 & 1.526 \\
\hline $\begin{array}{l}\text { Brown/black clutch } \\
\text { (Figure B3) }\end{array}$ & & & 4.580 & 1.606 \\
\hline $\begin{array}{l}\text { Black leather clutch } \\
\text { (Figure B4) }\end{array}$ & & & 4.919 & 1.388 \\
\hline $\begin{array}{l}\text { Long black silk dress } \\
\text { (Figure A5) }\end{array}$ & 2.154 & 1.566 & 2.735 & 1.685 \\
\hline $\begin{array}{l}\text { Long black winkle dress } \\
\text { (Figure A6) }\end{array}$ & 2.382 & 1.640 & 2.779 & 1.551 \\
\hline $\begin{array}{l}\text { White miniskirt } \\
\text { (Figure B5) }\end{array}$ & 4.474 & 1.499 & 4.896 & 1.329 \\
\hline $\begin{array}{l}\text { Yellow short dress } \\
\text { (Figure B6) }\end{array}$ & 4.279 & 1.412 & 4.580 & 1.320 \\
\hline $\begin{array}{l}\text { Black long-sleeve blouse } \\
\text { (Figure A7) }\end{array}$ & 3.147 & 1.713 & 3.978 & 1.588 \\
\hline $\begin{array}{l}\text { White plain long-sleeve shirt } \\
\text { (Figure A8) }\end{array}$ & 2.867 & 1.800 & 3.674 & 1.641 \\
\hline $\begin{array}{l}\text { Black sequin tank top } \\
\text { (Figure B7) }\end{array}$ & 5.333 & 1.822 & 5.067 & 1.929 \\
\hline $\begin{array}{l}\text { Yellow tank top } \\
\text { (Figure B8) }\end{array}$ & 4.792 & 1.506 & 5.051 & 1.384 \\
\hline
\end{tabular}

cycles was conducted. For this study, data from a group of 100 Vietnamese women (mean age $=28.45$ years, range from 21 to 37 years) different from the participants of the main study were obtained. To understand Vietnamese women's willingness to provide information on their ovulation cycles to marketers if they were compensated, a question "How much would you expect or ask for to provide your menstrual/ovulation information to marketers/companies?" was asked. All participating women indicated that they were willing to provide such information if they were compensated. Then, the participants were asked to write 
down the exact amount they would like to be paid for this information. On average, the women in this study expected to be paid US\$4.50, with a maximum of US\$25.

\subsection{Sample and Procedures}

Female participants were recruited in-person at a large well-known women's hospital in Vietnam. All participants were pre-screened to determine if they had regular menstrual cycles (e.g., cycles running 25 - 35 days) and whether they were using any hormonal contraception. Only those who had regular cycles and were not using hormonal contraceptives were included in the sample and invited for ovulation tests and surveys. The reason here for such selection is that all ovulatory shift effects disappear completely when women are using hormonal contraception (e.g., hormonal birth control pills and vaginal contraceptive rings such as NuvaRing) [5]. In detail, because contraception disrupts the normal fluctuation of hormones across the menstrual cycle, it erases the shifts associated with normal ovulation [6].

Sixty-six qualified females (Mage $=32.090, \mathrm{SD}=9.045, \min _{\text {age }}=18$ and $\max _{\text {age }}$ $=45$ ) were recruited (see Table 2 for the demographic characteristics of the sample).

The women to be included in the sample did an ovulation test to determine where they were in their cycles. If they tested at low fertility, they were invited back for a second test when at peak fertility. If they tested at high fertility, they were invited for a second test when at low fertility. That is, all participants indicated their attitudes and purchase intentions towards sexy and revealing fashion products at two times (peak fertility and low fertility). Obviously, the current study employed a within-subject design rather than a between-subject design.

Table 2. Sample characteristics.

\begin{tabular}{ccc}
\hline & Frequency & Percentage \\
\hline Age & 30 & \\
20 to $<30$ & 13 & $46.2 \%$ \\
30 to $<40$ & 20 & $20.0 \%$ \\
40 to $<50$ & Monthly income brackets (US Dollars) & $30.7 \%$ \\
& 5 & $11.9 \%$ \\
$<187.5^{1}$ & 12 & $28.6 \%$ \\
$\$ 187.5$ to $<\$ 300^{2}$ & 25 & $59.5 \%$ \\
$\$ 300 \$+$ & 39 & $62.9 \%$ \\
Education & 7 & $11.3 \%$ \\
Undergraduate & & \\
Master or above & & \\
\hline
\end{tabular}

${ }^{1}$ Minimum salary/month in 2017 regulated by the Vietnamese government ("Mứclươngtốithiểutại Việt Nam ápdụngtừngày 01-01-2017 đến 31-12-2017" (2016), equivalent to USD with exchange rate of 1 USD = 20,000 VND. ${ }^{2}$ Average income/month in 2017 in Vietnam (Thuy An, 2017). 
Within-subject includes three important advantages [35]. First, their internal validity does not depend on random assignment. This is a very important characteristic for this current study, because it would be impossible to randomly assign women to either the "ovulating" or "non-ovulating" condition. Second, they are often more aligned with the researchers' underlying theoretical framework. For example, in the current study, the research question relates to how one woman changes her attitudes and behavioral intentions towards sexy clothing based on hormonal shifts, and not how two different women behave independently based on their individual hormone levels. Third, within-subject design typically offers a substantially higher statistical power than equivalent between-subject designs. Indeed, previous studies support the use of within-subject over between-subject designs in order to increase power [36]. As a result, fewer participants are needed to detect a mean difference between two conditions in a within-subjects design (in a dependent t-test) than in a between-subjects design (in an independent t-test).

On the first ovulation test, $70.7 \%$, of the women were at low fertility, primarily because women are naturally not fertile for most of the month. Once participants' fertility condition was determined, they were given a survey designed to understand their opinions on how the clothing and accessories shown were more or less suitable for specific occasions. A scenario based on [4] and [5] was employed to define a specific occasion. Participants were asked to imagine that they were invited to a large evening birthday party that would be attended by many single, attractive men and women. They were then asked first to visualize what the guests would likely be wearing, and then they were to imagine what outfit they would like to wear. They were then asked to evaluate an array of products according to what they would be most inclined to wear.

\subsection{Measures}

Measures for attitudes, purchase intentions, fashion consciousness, and self-control were adapted from existing scales in the extant literature. Following [37] [38] and [39], we measured attitudes towards sexy and revealing fashion products with five items on a seven-point semantic scale (extremely dislike/extremely like, extremely unappealing/extremely appealing, extremely awful/ extremely nice, bad/good, and negative/positive). Cronbach's Alpha values for the attitudes scale were greater than 0.90 on all eight sexy products for both ovulating and non-ovulating subsamples. The Composite Reliability (CR) of each construct was 0.901 or above, and the Average Variance Extracted (AVE) of each construct was 0.647 or above. Thus, reliability and convergent validity were achieved.

Purchase intention was rated on responses to five items (e.g., "It is possible that I would buy this product") that assessed how likely participants would be to purchase selected clothing accessories. The five items were adapted from [37] and [40], and evaluated on a seven-point Likert scale anchored from 1 (strongly disagree) to 7 (strongly agree). The CR of each construct was 0.928 or above, and 
the AVE of each construct was 0.720 or above. Cronbach's Alpha values were 0.947 or more on all eight sexy and revealing products for both ovulating and non-ovulating subsamples.

We measured sexy fashion consciousness using three items based on [25] to assess to what extent participants were interested in wearing fashionable clothes or fashion-related accessories. This three-item construct was evaluated using a seven-point Likert scale anchored with 1 (strongly disagree) and 7 (strongly agree). The Cronbach's Alpha of this construct was 0.725. The CR was 0.851, and the AVE was 0.656 , which reflected acceptable levels of reliability and convergent validity.

Three Paired-Sample T-Tests were run on SPSS to compare the means on the three items when women were near ovulation vs. when not near ovulation. The results identified that differences between the means at the two critical points in time were not significant $(p>0.05)$. Thus, the average of all inputs was calculated as the general fashion consciousness trait of the participants.

Finally, to evaluate self-control (i.e., participants' emotions, thoughts, and behaviors in the face of temptation and impulse), we adapted four items from [41]. Cronbach's Alpha for this construct was 0.750, the CR was 0.844, and the AVE was 0.581 , thus demonstrating acceptable levels of reliability and convergent validity.

Similar to the case of fashion consciousness construct, we conducted three paired-sample t-tests on SPSS to compare the means on the three items when women were near ovulation vs. when not near ovulation. The results indicated that there was no significant difference when women were not ovulation and when not near ovulation $(p>0.05)$. Thus, the average of all inputs was calculated as the general self-control trait of the participants.

\section{Results}

\subsection{Effect of Ovulation on Attitudes}

The results from paired-sample t-tests showed a significant and substantial effect of ovulation on attitudes towards sexy and revealing fashion products. Specifically, respondents showed more favorable attitudes towards sexy and revealing fashion products when they were at peak fertility, as compared to when they were at low fertility (Table 3 ). Further, the effect sizes for these differences ranged from 0.57 to 0.86 and were thus substantial [42]. For example, attitudes for "red heals" were significantly more favorable at peak fertility $(\mathrm{M}=5.44, \mathrm{SD}=1.09)$ than at low fertility $(\mathrm{M}=4.66, \mathrm{SD}=1.32, \mathrm{t}=5.85, p<0.001, \mathrm{~d}=0.73)$. Concluding, supports for H1a for all eight products were found.

\subsection{Effect of Ovulation on Purchase Intentions}

Congruent with the attitude tests above, the results from the paired-sample t-tests indicated a significant effect of ovulation on purchase intentions for sexy and revealing fashion products. That is, women at peak fertility did not only 
Table 3. Attitudes towards sexy and revealing fashion products during peak and low fertility.

\begin{tabular}{cccccc}
\hline \multirow{2}{*}{ Sexy Fashion Products } & Peak fertility & Low fertility & t-value & p-value & Effect size \\
\cline { 2 - 6 } & Mean (SD) & Mean (SD) & & & (Cohen's d) \\
\hline Red heels (Figure A1) & $5.44(1.09)$ & $4.66(1.32)$ & 5.85 & $<0.001$ & 0.73 \\
Golden heels (Figure A2) & $5.28(1.34)$ & $4.78(1.39)$ & 4.44 & $<0.001$ & 0.86 \\
Brown/black handbag (Figure A3) & $5.08(1.35)$ & $4.49(1.42)$ & 4.64 & $<0.001$ & 0.57 \\
Black leather handbag (Figure A4) & $5.37(1.13)$ & $4.77(1.13)$ & 4.70 & $<0.001$ & 0.57 \\
White miniskirt (Figure A5) & $5.40(1.11)$ & $4.78(1.29)$ & 4.78 & $<0.001$ & 0.59 \\
Yellow short dress (Figure A6) & $5.07(1.20)$ & $4.45(1.29)$ & 5.43 & $<0.001$ & 0.68 \\
Black sequin tank top (Figure A7) & $4.55(1.66)$ & $3.70(1.63)$ & 4.92 & $<0.001$ & 0.61 \\
Yellow tank top (Figure A8) & $5.30(1.27)$ & $4.52(1.58)$ & 5.89 & $<0.001$ & 0.76 \\
\hline
\end{tabular}

show more favorable attitudes towards the target products, but also had higher intentions to actually purchase these items (Table 4). For example, women had a significantly higher purchase intention for red heels at peak fertility $(M=5.19$, $\mathrm{SD}=1.31)$ than at low fertility $(\mathrm{M}=4.40, \mathrm{SD}=1.51, \mathrm{t}=4.88, p<0.001, \mathrm{~d}=$ $0.61)$.

\subsection{Mediation of Attitudes}

H1a predicted a positive effect of ovulation on attitudes towards sexy and revealing fashion products, and $\mathrm{H} 1 \mathrm{~b}$ predicted an indirect effect of ovulation on purchase intentions. The results of these tests provided evidence in support of the Ovulatory Shift Hypothesis (OSH). However, the Theory of Reasoned Action (TRA) presumes that attitudes predict purchase intentions. To test TRA in the context of women's ovulatory shifts, we ran a formal mediation model that included attitudes towards sexy and revealing fashion products as a mediator for the relationship between ovulation and purchase intentions.

Testing mediation effects for within-subject designs (i.e., repeated measures) is challenging because contrary to between-subject designs, the assumption of independent observations is violated. Thus, running, e.g., the increasingly popular Hayes' [43] process macro on the data here was not possible. However, recent advances in statistics have made available a dedicated macro for mediation tests of within-subjects designs [7]. Running this new macro allowed us to formally test the mediating effect of attitudes, as shown in Figure 1, as predicted in H1b.

Mediation occurs when the indirect effect from the independent variable $\mathrm{X}$ to the dependent variable $\mathrm{Y}$ through the mediator $\mathrm{M}$ is statistically significant. The results of the mediation analyses showed a statistically significant indirect effect of attitudes towards sexy and revealing fashion products for all eight target products (Table 4). Specifically, for all eight products, the 95\% bias-corrected bootstrapping confidence interval for the indirect effect did not include zero (and thus indicated statistical significance). For example, the indirect effect of attitudes for 


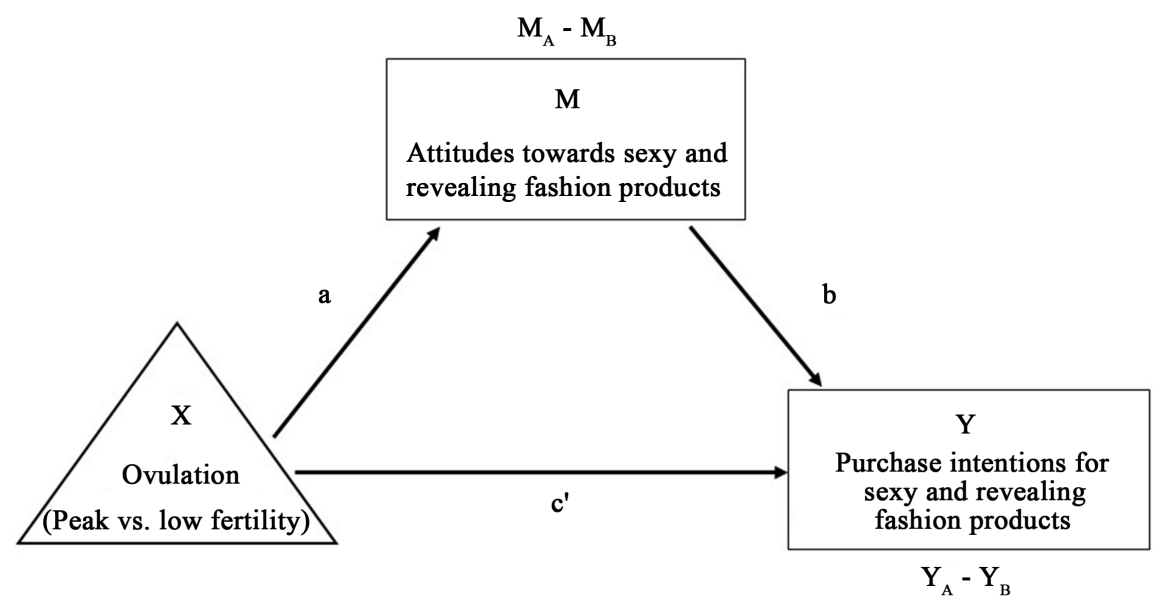

Figure 1. Mediation model for within-subject design (Montoya \& Hayes, 2017).

Table 4. Purchase intentions for sexy and revealing fashion products during peak and low fertility.

\begin{tabular}{cccccc}
\hline \multirow{2}{*}{ Sexy Fashion Products } & Peak fertility & Low fertility & t-value & p-value & Effect size \\
\cline { 2 - 5 } & Mean (SD) & Mean (SD) & & & (Cohen's d) \\
\hline Red heels (Figure A1) & $5.19(1.31)$ & $4.40(1.51)$ & 4.88 & $<0.001$ & 0.61 \\
Golden heels (Figure A2) & $5.17(1.41)$ & $4.31(1.60)$ & 5.55 & $<0.001$ & 0.70 \\
Brown/black handbag (Figure A3) & $4.73(1.46)$ & $4.10(1.58)$ & 3.42 & $<0.01$ & 0.42 \\
Black leather handbag (Figure A4) & $5.03(1.31)$ & $4.40(1.38)$ & 4.72 & $<0.001$ & 0.58 \\
White miniskirt (Figure A5) & $4.94(1.32)$ & $4.37(1.50)$ & 4.03 & $<0.001$ & 0.50 \\
Yellow short dress (Figure A6) & $4.81(1.34)$ & $4.28(1.43)$ & 4.50 & $<0.001$ & 0.56 \\
Black sequin tank top (Figure A7) & $3.89(1.57)$ & $3.25(1.51)$ & 3.21 & $<0.01$ & 0.40 \\
Yellow tank top (Figure A8) & $4.82(1.31)$ & $4.20(1.47)$ & 4.03 & $<0.001$ & 0.51 \\
\hline
\end{tabular}

reed heels was 0.261 , with a $95 \%$ bias-corrected bootstrapping confidence interval ranging from 0.035 to 0.588 . Thus, the results here provide evidence in support of $\mathrm{H} 2$.

As can be also seen from Table 5, after inclusion of the mediator, the direct effect for the influence of ovulation on purchase intentions remained statistically significant in five cases and disappeared in three cases. Thus, for the brown/black handbag, the black sequin tank top, and the yellow tank top, full mediation was observed, whereas for the other five products, partial mediation occurred. Overall, these tests corroborate H1b.

\subsection{Moderating Effects of Sexy Fashion Consciousness and Self-Control}

Because of the dependence of observations in within-subject designs, similar problems for the moderation tests were encountered in the testing of mediation. Unfortunately, Montoya and Hayes' [7] current version of the MEMORE macro has implemented the testing of mediation, but algorithms for testing moderation 
Table 5. Mediation of attitudes towards sexy and revealing fashion products.

\begin{tabular}{ccccccc}
\hline & \multicolumn{3}{c}{ Indirect Effect } & \multicolumn{3}{c}{ Direct Effect } \\
\cline { 2 - 7 } Sexy Fashion Products & b & LLCI & ULCI & b & t-value & $p$-value \\
\hline Red heels (Figure A1) & 0.261 & 0.035 & 0.588 & 0.523 & 2.675 & $<0.01$ \\
Golden heels (Figure A2) & 0.241 & 0.015 & 0.558 & 0.611 & 3.667 & $<0.001$ \\
Brown/black handbag (Figure A3) & 0.482 & 0.216 & 0.820 & 0.146 & 0.824 & $n s$ \\
Black leather handbag (Figure A4) & 0.256 & 0.079 & 0.528 & 0.375 & 2.629 & $<0.05$ \\
White miniskirt (Figure A5) & 0.221 & 0.007 & 0.461 & 0.349 & 2.212 & $<0.05$ \\
Yellow short dress (Figure A6) & 0.179 & 0.054 & 0.353 & 0.349 & 2.525 & $<0.05$ \\
Black sequin tank top (Figure A7) & 0.421 & 0.167 & 0.757 & 0.209 & 1.016 & $n s$ \\
Yellow tank top (Figure A8) & 0.272 & 0.016 & 0.551 & 0.343 & 1.814 & $n s$ \\
\hline
\end{tabular}

Note: Confidence interval $=95 \%$. Number of bootstrap samples $=5000$. Indirect and direct effects are calculated based on Montoya and Hayes' (2017) MEMORE macro for within-subject designs.

were still under development at the time this article was written. As an alternative, recommendations by [44] and regressed the difference of the $\mathrm{Y}$ variable (i.e., attitudes towards sexy and revealing fashion products) on the moderator (formula [6], p. 119) were followed. Although for some of the eight target products, the sign of the effect pointed in the expected direction (positive for fashion consciousness and negative for self-control), very few of these effects were statistically significant. Thus, evidence in support of $\mathrm{H} 3 \mathrm{a}$ (moderating effect of fashion consciousness) and H3b (moderating effect of self-control) were not able to be detected.

\section{Discussion}

The findings described above enhance the understanding of women's attitudes and purchase intentions toward sexy and revealing fashion products when they are near ovulation. This research shows that women's attitudes and purchase intentions towards sexy and revealing fashion products are more favorable when near peak fertility. In other words, women near ovulation show more interest in and a stronger preference for provocative, sexual fashion items.

For all eight target products, an indirect relationship between ovulation and purchase intention toward such products was observed. These findings shed light on how female sex hormones, when at peak fertility, indirectly impact purchase intention toward sexy and revealing products, with attitude change as mediator. This result strongly suggests that ovulation, attitude, and purchase intention toward these fashions form a sequential relationship.

However, the findings demonstrate that such psychological characteristics as fashion consciousness and self-control do have any moderating influence on the relationship between women's ovulation and their attitude toward sexy and revealing fashion products. 


\subsection{Theoretical Contribution}

This study offers several contributions to theory. First, it adds to related streams of research which suggest that hormonal fluctuations influence consumers' attitudes and purchase intentions (see, e.g., [5] [18]). As predicted by the Ovulatory Shift Hypothesis [9], the results here show that women at peak fertility develop more favorable attitudes and stronger purchase intentions towards sexy and revealing fashion products, as compared to women at low fertility. Because this research uses a within-subject design and thus women indicated their attitudes and purchase intentions both a peak and at low fertility, the results are more robust than if a between-subject design had been used, where self-selection bias would have been a problem. Overall, the findings of this study suggest that marketing can only work if marketers have a reasonably accurate view of human nature, as being emphasized in [45]. In detail, [45] emphasize the significance of connections between marketing practices and evolved adaptations, including kin selection and prestige seeking.

Second, as predicted by the Theory of Reasoned Action [22] [23], a mediating effect of attitudes for the relationship between ovulation and purchase intentions towards sexy and revealing fashion products was observed. To test this relationship, a relatively recent advancement in statistical analysis for within-subject mediation models, the MEMORE macro [7] was used. Third, followed the call for more theory-driven research in emerging economies [8], this study was situated in Vietnam, an Asian country that is culturally different from the Western setting of previous research on consumer-related OSH research.

\subsection{Managerial Implications}

This research helps marketing practitioners understand how women's fashion choices are influenced by underlying biological factors. This understanding can help fashion brands (e.g. luxury brands) craft an effective marketing strategy targeting women at peak fertility. For example, these companies could gather the female consumers' ovulation data and send ads of sexy and revealing fashion items via texts or emails to women near ovulation.

Basing on the results from the survey on how likely Vietnamese women are to provide information of their ovulation cycle; we assert that companies in Vietnam would be able to obtain individual-level ovulation data to target consumers more effectively.

\section{Limitations and Avenues for Future Research}

This study provides important insight on the relationship between women's hormonal functions and specific attitudes and purchase intentions towards sexy and revealing fashion products. Future research may try to investigate the effects shown in this research in depth.

For example, this research does not include may-be-relevant theories of sexual selection [46], parental investment [47], and strategic pluralism [48] to help ex- 
plain the phenomenon. Sexual selection by [46] to address an apparent puzzle in the animal kingdom: Given that natural selection generally favors traits that aid survival, it was initially unclear why some animal traits appear to confer no functional advantages and may even impede survival. Parental investment [47] is the contribution that each parent makes to the production of viable (i.e., reproducing) offspring. Strategic pluralism theory [48] evidences how factors such as one's desirability to the opposite sex (i.e. mate value), current economic and environmental conditions, and local sex ratios influence one's choice on a long-term, high-investing strategy (i.e., a restricted strategy) versus a short-term, non-investing strategy (i.e., an unrestricted strategy).

Second, this study did not investigate in-depth into the intrasexual competition (competing with same sex direct rivals) or intersexual competition (competing for attention of potential mate). In other words, the deep motivation behind mating purposes (i.e. mate retention vs mate acquisition) for women preferring more revealing/sexy fashion products and selecting such products will not be explained in this study.

A third avenue for future research is related to the deep motivation behind mating purposes (i.e., mate retention vs. mate acquisition) of women who prefer sexy and revealing products at peak ovulation.

Forth, future research may investigate the role of fashion consciousness, self-control, and other personality-related factors that potentially moderate the relationships shown in this study.

Finally, a future study may use an updated version of the MEMORE macro to test for the hypothesized moderation effects in a more advanced way.

\section{References}

[1] Saad, G. and Gill, T. (2000) Applications of Evolutionary Psychology in Marketing. Psychology and Marketing, 17, 1005-1034. https://doi.org/10.1002/1520-6793(200012)17:12<1005::AID-MAR1>3.0.CO;2-H

[2] Bagozzi, R.P. and Nataraajan, R. (2000) The Year 2000: Looking Forward. Psychology \& Marketing, 17, 1-11. https://doi.org/10.1002/(SICI)1520-6793(200001)17:1<1::AID-MAR1>3.0.CO;2-Y

[3] Workman, J.E. and Studak, C.M. (2007) Relationships among Fashion Consumer Groups, Locus of Control, Boredom Proneness, Boredom Coping and Intrinsic Enjoyment. International Journal of Consumer Studies, 31, 66-75. https://doi.org/10.1111/j.1470-6431.2005.00486.x

[4] Durante, K.M., Li, N.P. and Haselton, M.G. (2008) Changes in Women's Choice of Dress across the Ovulatory Cycle: Naturalistic and Laboratory Task-Based Evidence. Personality and Social Psychology Bulletin, 34, 1451-1460. https://doi.org/10.1177/0146167208323103

[5] Durante, K.M., Griskevicius, V., Hill, S.E., Perilloux, C. and Li, N.P. (2011) Ovulation, Female Competition, and Product Choice: Hormonal Influences on Consumer Behavior. Journal of Consumer Research, 37, 921-934. https://doi.org/10.1086/656575

[6] Fleischman, D.S., Navarrete, C.D. and Fessler, D.M. (2010) Oral Contraceptives Suppress Ovarian Hormone Production. Psychological Science, 21, 750-752. https://doi.org/10.1177/0956797610368062 
[7] Montoya, A.K. and Hayes, A.F. (2017) Two-Condition Within-Participant Statistical Mediation Analysis: A Path-Analytic Framework. Psychological Methods, 22, 6-27. https://doi.org/10.1037/met0000086

[8] Burgess, S.M. and Steenkamp, J.-B.E.M. (2013) Editorial: Introduction to the Special Issue on Marketing in Emerging Markets. International Journal of Research in Marketing, 30, 1-3. https://doi.org/10.1016/j.ijresmar.2013.01.001

[9] Gangestad, S.W., Thornhill, R. and Garver-Apgar, C.E. (2005) Women's Sexual Interests across the Ovulatory Cycle Depend on Primary Partner Developmental Instability. Proceedings of the Royal Society of London B: Biological Sciences, 272, 2023-2027. https://doi.org/10.1098/rspb.2005.3112

[10] Bunting, L. and Boivin, J. (2008) Knowledge about Infertility Risk Factors, Fertility Myths and Illusory Benefits of Healthy Habits in Young People. Human Reproduction, 23, 1858-1864. https://doi.org/10.1093/humrep/den168

[11] Gangestad, S.W. and Thornhill, R. (1998) Menstrual Cycle Variation in Women's Preferences for the Scent of Symmetrical Men. Proceedings of the Royal Society of London B: Biological Sciences, 265, 927-933. https://doi.org/10.1098/rspb.1998.0380

[12] Wang, Y. and Griskevicius, V. (2014) Conspicuous Consumption, Relationships, and Rivals: Women's Luxury Products as Signals to Other Women. Journal of Consumer Research, 40, 834-854. https://doi.org/10.1086/673256

[13] Sundie, J.M., Kenrick, D.T., Griskevicius, V., Tybur, J.M., Vohs, K.D. and Beal, D.J. (2011) Peacocks, Porsches, and Thorstein Veblen: Conspicuous Consumption as a Sexual Signaling System. Journal of Personality and Social Psychology, 100, 664. https://doi.org/10.1037/a0021669

[14] Benz, J.J., Anderson, M.K. and Miller, R.L. (2005) Attributions of Deception in Dating Situations. The Psychological Record, 55, 305. https://doi.org/10.1007/BF03395512

[15] Griskevicius, V. and Kenrick, D.T. (2013) Fundamental Motives: How Evolutionary Needs Influence Consumer Behavior. Journal of Consumer Psychology, 23, 372-386. https://doi.org/10.1016/j.jcps.2013.03.003

[16] Fessler, D.M. (2003) No Time to Eat: An Adaptationist Account of Periovulatory Behavioral Changes. The Quarterly Review of Biology, 78, 3-21. https://doi.org/10.1086/367579

[17] Gangestad, S.W., Thornhill, R. and Garver, C.E. (2002) Changes in Women's Sexual Interests and Their Partner's Mate-Retention Tactics across the Menstrual Cycle: Evidence for Shifting Conflicts of Interest. Proceedings of the Royal Society of London B: Biological Sciences, 269, 975-982. https://doi.org/10.1098/rspb.2001.1952

[18] Saad, G. and Stenstrom, E. (2012) Calories, Beauty, and Ovulation: The Effects of the Menstrual Cycle on Food and Appearance-Related Consumption. Journal of Consumer Psychology, 22, 102-113. https://doi.org/10.1016/j.jcps.2011.10.001

[19] Kenrick, D.T. and Keefe, R.C. (1992) Age Preferences in Mates Reflect Sex Differences in Human Reproductive Strategies. Behavioral and Brain Sciences, 15, 75-91. https://doi.org/10.1017/S0140525X00067595

[20] Wiederman, M.W. (1993) Evolved Gender Differences in Mate Preferences: Evidence from Personal Advertisements. Ethology and Sociobiology, 14, 331-351. https://doi.org/10.1016/0162-3095(93)90003-Z

[21] Haselton, M.G., Mortezaie, M., Pillsworth, E.G., Bleske-Rechek, A. and Frederick, D.A. (2007) Ovulatory Shifts in Human Female Ornamentation: Near Ovulation, Women Dress to Impress. Hormones and Behavior, 51, 40-45. https://doi.org/10.1016/j.yhbeh.2006.07.007 
[22] Ajzen, I. (1985) From Intentions to Actions: A Theory of Planned Behavior. In: Kuhl, J. and Beckmann, J., Eds., Action Control, Springer, Heidelberg, 11-39. https://doi.org/10.1007/978-3-642-69746-3_2

[23] Ajzen, I. (2002) Perceived Behavioral Control, Self-Efficacy, Locus of Control, and the Theory of Planned Behavior. Journal of Applied Social Psychology, 32, 665-683. https://doi.org/10.1111/j.1559-1816.2002.tb00236.x

[24] Vermeir, I. and Verbeke, W. (2006) Sustainable Food Consumption: Exploring the Consumer "Attitude-Behavioral Intention" Gap. Journal of Agricultural and Environmental Ethics, 19, 169-194. https://doi.org/10.1007/s10806-005-5485-3

[25] Stephen Parker, R., Hermans, C.M. and Schaefer, A.D. (2004) Fashion Consciousness of Chinese, Japanese and American Teenagers. Journal of Fashion Marketing and Management. An International Journal, 8, 176-186. https://doi.org/10.1108/13612020410537870

[26] Kashima, Y., Yamaguchi, S., Kim, U., Choi, S.C., Gelfand, M.J. and Yuki, M. (1995) Culture, Gender, and Self: A Perspective from Individualism-Collectivism Research. Journal of Personality and Social Psychology, 69, 925-937. https://doi.org/10.1037/0022-3514.69.5.925

[27] Wheeler, L., Reis, H.T. and Bond, M.H. (1989) Collectivism-Individualism in Everyday Social Life: The Middle Kingdom and the Melting Pot. Journal of Personality and Social Psychology, 57, 79-86. https://doi.org/10.1037/0022-3514.57.1.79

[28] Gutman, J. and Mills, M.K. (1982) Fashion Life-Style, Self-Concept, Shopping Orientation, and Store Patronage-An Integrative Analysis. Journal of Retailing, 58, 64-86.

[29] Summers, J.O. (1970) The Identity of Women's Clothing Fashion Opinion Leaders. Journal of Marketing Research, 7, 178-185. https://doi.org/10.2307/3150106

[30] O'Cass, A. (2000) An Assessment of Consumers Product, Purchase Decision, Advertising and Consumption Involvement in Fashion Clothing. Journal of Economic Psychology, 21, 545-576. https://doi.org/10.1016/S0167-4870(00)00018-0

[31] Cardoso, P.R., Costa, H.S. and Novais, L.A. (2010) Fashion Consumer Profiles in the Portuguese Market: Involvement, Innovativeness, Self-Expression and Impulsiveness as Segmentation Criteria. International Journal of Consumer Studies, 34, 638-647. https://doi.org/10.1111/j.1470-6431.2010.00891.x

[32] Naderi, I. (2013) Beyond the Fad: A Critical Review of Consumer Fashion Involvement. International Journal of Consumer Studies, 37, 84-104. https://doi.org/10.1111/j.1470-6431.2011.01041.x

[33] Baumeister, R.F., Sparks, E.A., Stillman, T.F. and Vohs, K.D. (2008) Free Will in Consumer Behavior: Self-Control, Ego Depletion, and Choice. Journal of Consumer Psychology, 18, 4-13. https://doi.org/10.1016/j.jcps.2007.10.002

[34] Hoch, S.J. and Loewenstein, G.F. (1991) Time-Inconsistent Preferences and Consumer Self-Control. Journal of Consumer Research, 17, 492-507. https://doi.org/10.1086/208573

[35] Charness, G., Gneezy, U. and Kuhn, M.A. (2012) Experimental Methods: Between-Subject and Within-Subject Design. Journal of Economic Behavior \& Organization, 81, 1-8. https://doi.org/10.1016/j.jebo.2011.08.009

[36] Maxwell, S.E. and Delaney, H.D. (2004) Designing Experiments and Analyzing Data: A Model Comparison Perspective. 2nd Edition, Lawrence Erlbaum Associates, Mahwah.

[37] Baker, M.J. and Churchill Jr, G.A. (1977) The Impact of Physically Attractive Models on Advertising Evaluations. Journal of Marketing Research, 14, 538-555. https://doi.org/10.2307/3151194 
[38] Miniard, P.W., Bhatla, S., Lord, K.R., Dickson, P.R. and Unnava, H.R. (1991) Picture-Based Persuasion Processes and the Moderating Role of Involvement. Journal of Consumer Research, 18, 92-107. https://doi.org/10.1086/209244

[39] Miniard, P.W., Sirdeshmukh, D. and Innis, D.E. (1992) Peripheral Persuasion and Brand Choice. Journal of Consumer Research, 19, 226-239. https://doi.org/10.1086/209298

[40] Lu, L.C., Chang, W.P. and Chang, H.H. (2014) Consumer Attitudes toward Blogger's Sponsored Recommendations and Purchase Intention: The Effect of Sponsorship Type, Product Type, and Brand Awareness. Computers in Human Behavior, 34, 258-266. https://doi.org/10.1016/j.chb.2014.02.007

[41] Tangney, J.P., Baumeister, R.F. and Boone, A.L. (2004) High Self-Control Predicts Good Adjustment, Less Pathology, Better Grades, and Interpersonal Success. Journal of Personality, 72, 271-324. https://doi.org/10.1111/j.0022-3506.2004.00263.x

[42] Cohen, J. (1988) Statistical Power Analysis for the Behavioral Sciences. Routledge, New York.

[43] Hayes, A.F. (2013) Introduction to Mediation, Moderation, and Conditional Process Analysis: A Regression-Based Approach. The Guilford Press, New York.

[44] Judd, C.M., Kenny, D.A. and McClelland, G.H. (2001) Estimating and Testing Mediation and Moderation in Within-Subject Designs. Psychological Methods, 6, 115-134. https://doi.org/10.1037/1082-989X.6.2.115

[45] Colarelli, S.M. and Dettmann, J.R. (2003) Intuitive Evolutionary Perspectives in Marketing Practices. Psychology \& Marketing, 20, 837-865. https://doi.org/10.1002/mar.10099

[46] Darwin, C. (1871) The Descent of Man and Selection in Relation to Sex. Princeton University Press, Princeton.

[47] Trivers, R.L. (1972) Parental Investment and Sexual Selection. In: Campbell, B.G., Ed., Sexual Selection and the Descent of Man, Aldine, Chicago, 136-179.

[48] Gangestad, S.W. and Simpson, J.A. (2000) The Evolution of Human Mating: Trade-Offs and Strategic Pluralism. Behavioral and Brain Sciences, 23, 573-587. https://doi.org/10.1017/S0140525X0000337X 


\section{Appendix A}

Less sexy and revealing fashion products used in the main study.

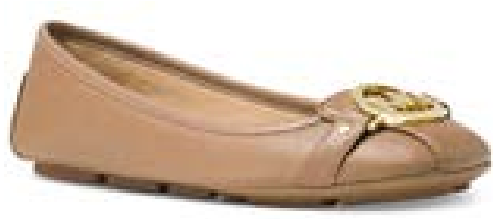

Figure A1. Brown flat shoes.

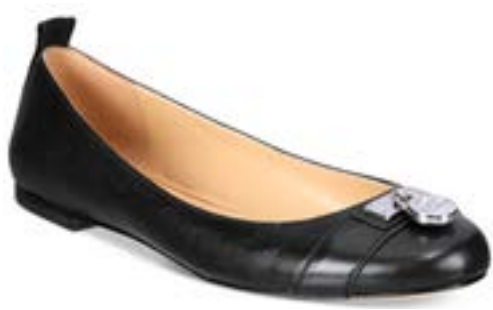

Figure A2. Black flat shoes.

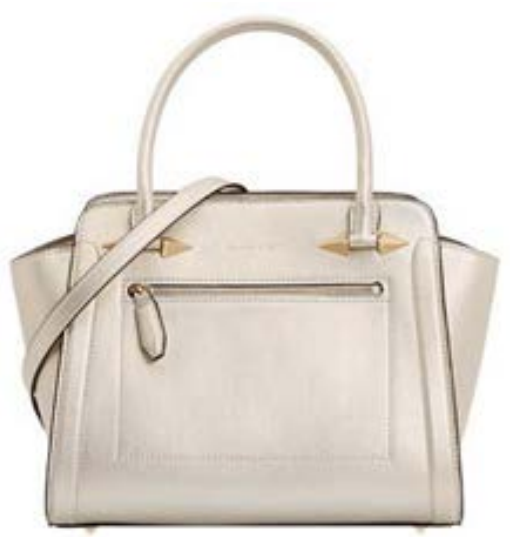

Figure A3. White handbag.

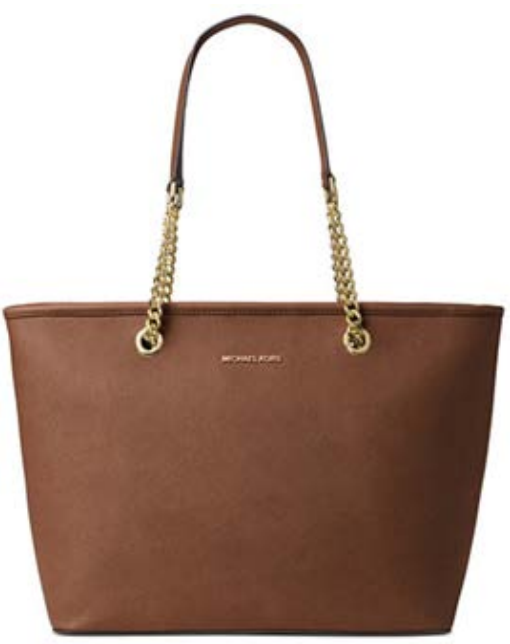

Figure A4. Brown/black evening clutch. 


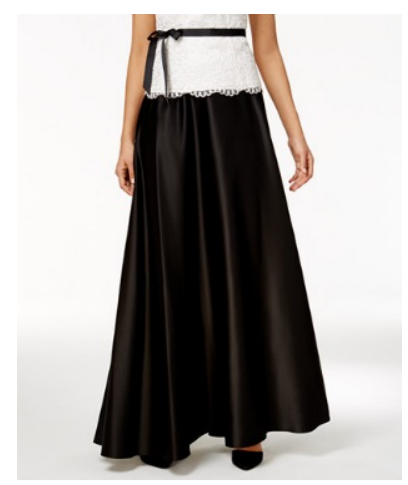

Figure A5. Long black silk dress.

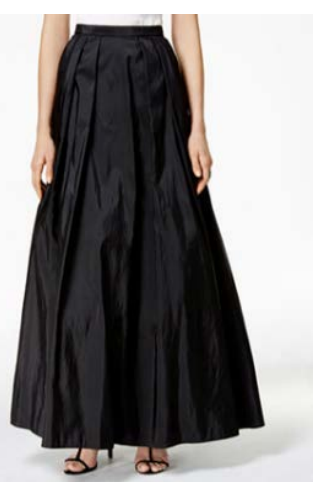

Figure A6. Long black winkle dress.

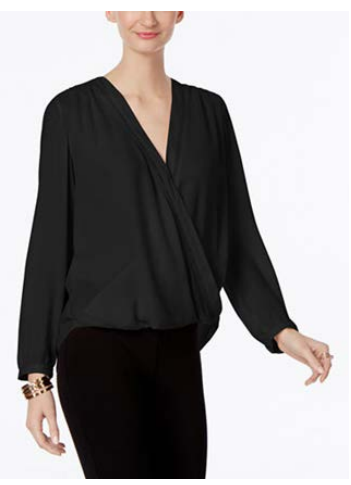

Figure A7. Black long-sleeve blouse.

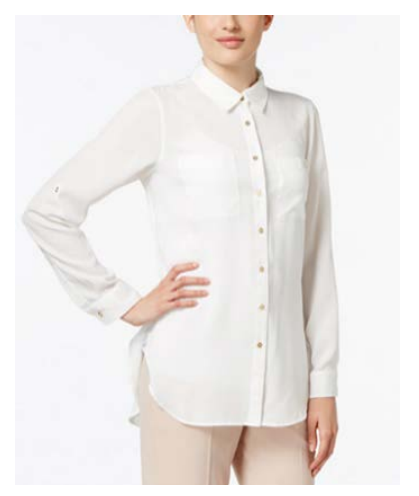

Figure A8. White plain long-sleeve. 


\section{Appendix B}

Sexy and revealing fashion products used in the main study.

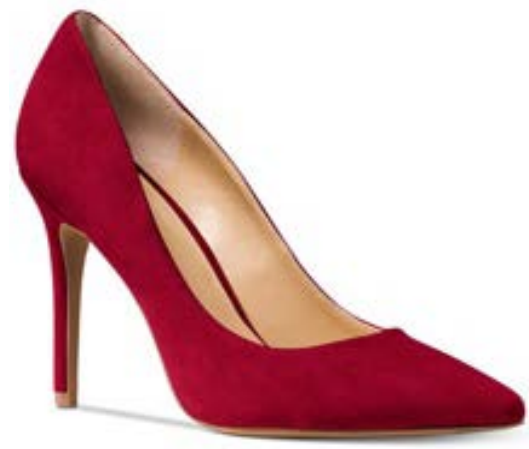

Figure B1. Red heels.

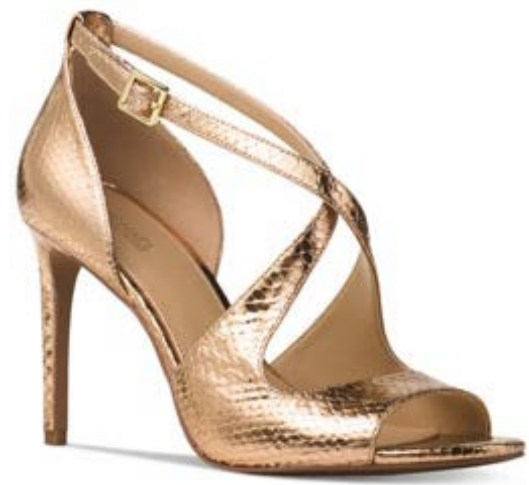

Figure B2. Golden heels.

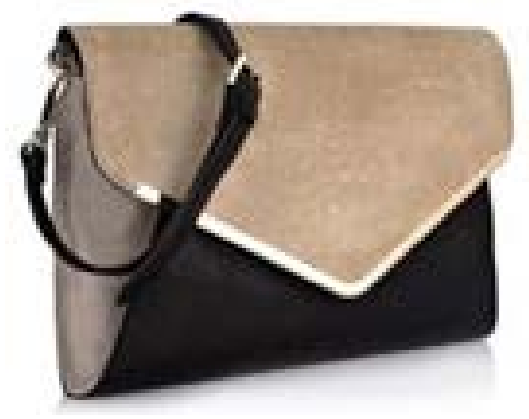

Figure B3. Brown/black handbag.

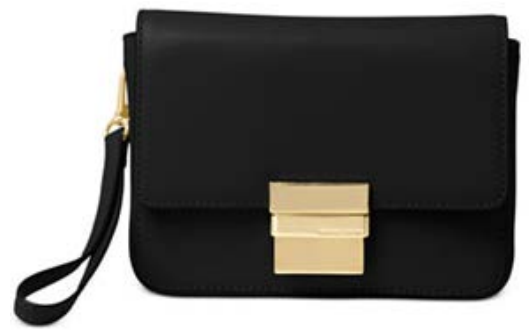

Figure B4. Black leather handbag. 


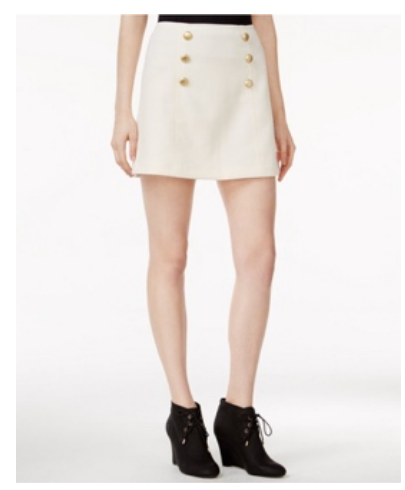

Figure B5. White miniskirt.

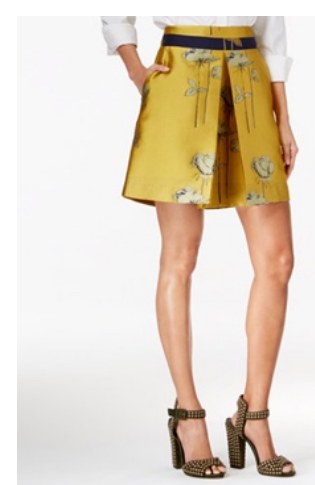

Figure B6. Yellow short dress.

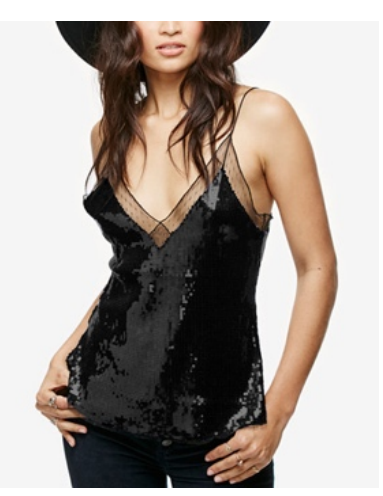

Figure B7. Black sequin tank top.

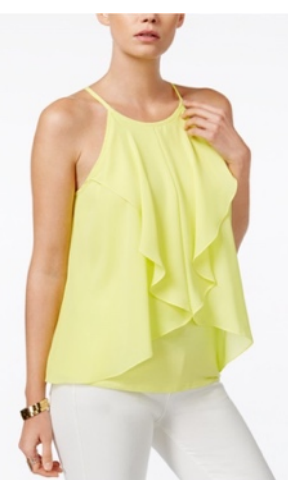

Figure B8. Yellow tank top. 